\title{
Cervical cord compression by solitary osteochondroma of the atlas
}

\author{
J . J U L I E N, V. R I E M E N S, C 1. V I T A L, A. L A G U E N Y, \\ A N D G. M I E T \\ From the Department of Neurology, Hôpital du Haut-Lévêque, Bordeaux-Pessac, France
}

\begin{abstract}
SUMMARY A 28 year old woman presented a syndrome of slow spinal compression evolving over four and a half years at the level $\mathrm{Cl}-\mathrm{C} 2$ vertebrae due to a solitary osteochondroma of the posterior arch of the atlas which was excised by laminectomy. Radiographs of the skeleton did not show the presence of other osteogenic tumours. This is the fifth case of solitary osteochondroma to be published. Elsewhere, in six cases out of 14, the vertebral lesion formed part of generalised exostoses.
\end{abstract}

Solitary exostoses are a rare cause of spinal cord compression. We have traced only four cases in the literature (Rose and Fekete, 1964; Thomas and Andress, 1971; Mitsumori et al., 1975; Twersky et al., 1975). We report here a fifth case, a young woman aged 28 years, who presented a left Brown-Séquard syndrome secondary to an exostosis of the posterior arch of the atlas.

\section{Case report}

A 28 year old woman was admitted to hospital in August 1976 with a four year history of a progressively increasing Brown-Séquard syndrome. On neurological examination a left hemiplegia and a right hypaesthesia to touch and pinprick up to C1-C2 dermatomes were found. During the same period the patient also developed an upper cervical pain which was made worse by rotation of the head.

Lumbar spinal fluid did not reveal any albumino-cytological dissociation. Lateral tomographic views of the cervico-occipital region showed, implanted on the lower surface of the atlas, a round, condensed image narrowing the cervical canal at this level (Figure). Lipiodol myelography completed by gas myelography confirmed, in double contrast, that there was compression of the spinal cord by an extradural space-occupying lesion opposite $\mathrm{C} 2$ vertebra. No osteogenic lesion was noted in the remainder of the skeleton.

Address for reprint requests: Professor A. J. Julien, Department of Neurology, Hôpital du Haut-Lévêque, Bordeaux-Pessac, France.

Accepted 11 November 1977
Operation was performed in early October 1976. A cervico-occipital incision disclosed a bone tumour. The posterior arch of the atlas was divided on both sides of the neoplasm and the compressed spinal cord which was liberated pushed out the bony fragment. This was a particularly hard lesion which was not specially adherent to the dural plane.

Pathological examination of the operative specimen confirmed that it was a benign osteochondroma.

\section{Discussion}

Exostoses are benign tumours consisting of a salient bone covered with cartilage arising from the cortex of the bone. They increase slowly in size in childhood and adolescence by endochondral ossification (Murray, 1969). They involve mainly the long but also the flat bones, and, exceptionally, the spinal cord $(2.5 \%$ according to Dahlin, 1970$)$ in their solitary form. They are more frequent in widespread exostoses $(7 \%)$.

Four similar cases have been reported. Rose and Fekete (1964) reported one case of sudden death in a 58 year old man from partial division of the cervical cord by an osteochondroma of the odontoid process. Thomas and Andress (1971) described a syndrome of slow spinal cord compression in a 21 year old man due to a pediculated osteochondroma of the right lamina of C6 vertebra. This patient was operated on successfully. Twersky et al. (1975) discovered a small osteochondroma of the posteroinferior angle of the body of L4 vertebra in a 13 year old child who 


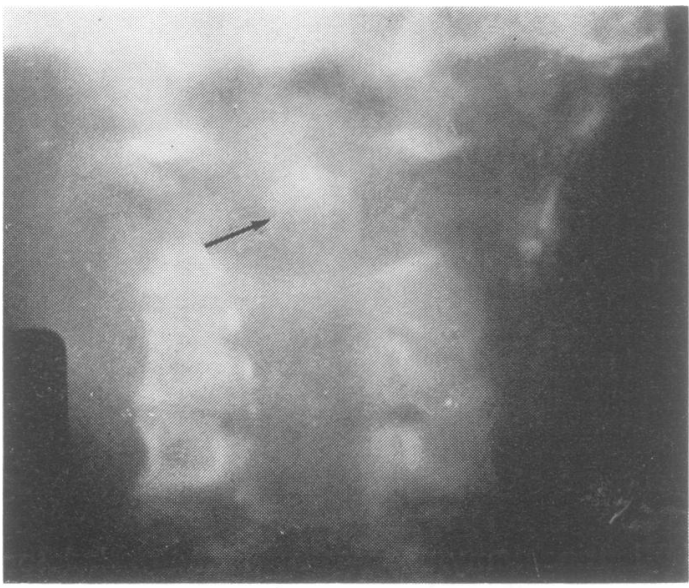

(a)

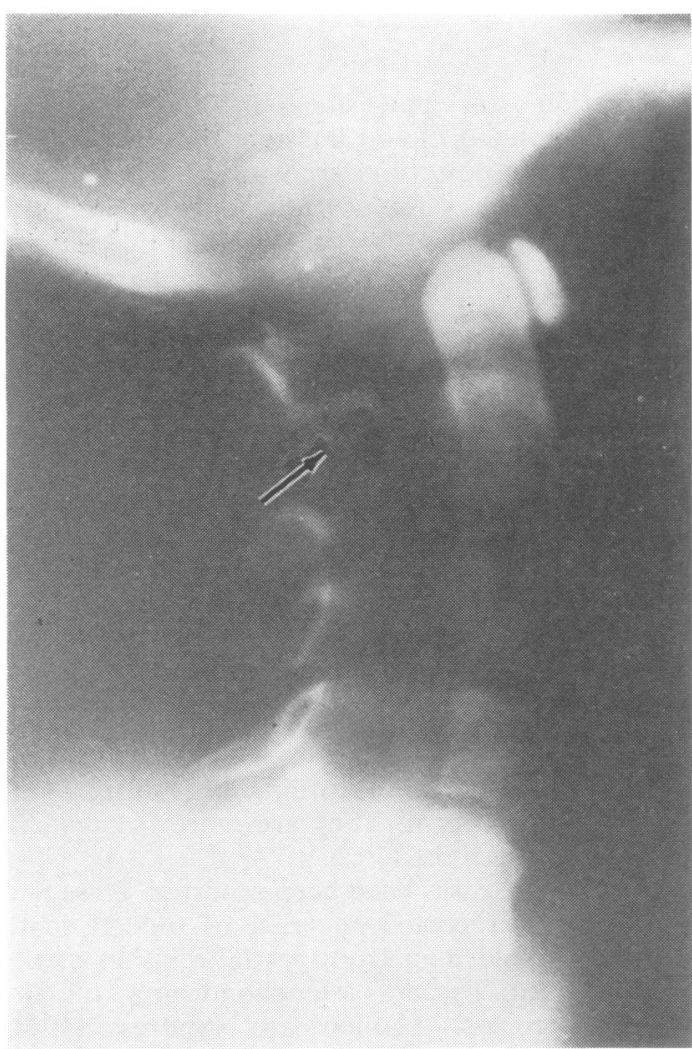

(b)

Figure Tomographic studies of cervical spine (a) frontal view and (b) lateral view. Arrows indicate osteochondroma. had been suffering for nine months from lumbar pain and bilateral sciatica. The tumour was excised avoiding compression of the nerve roots.

Mitsumori et al. (1975) reported the case of a 54 year old woman, suffering from neuralgia in the area supplied by $\mathrm{C} 1$ and $\mathrm{C} 2$ spinal nerves, with cervical stiffening evolving over seven years, who was operated on for left laterocervical osteochondroma filling the $\mathrm{C} 1 / 2$ intervertebral space. The operation, which required an anterolateral approach followed by excision of the tumour bit by bit, had to be completed by a graft, but postoperative recovery was good.

An osteochondroma may also compress the spinal cord when it develops from a rib at the level of the costovertebral junction. Natarajan et al. (1976) reported a 21 year old man who consulted for the onset over a period of two months of a deficiency of the lower limbs and urinary incontinence. The tumour was situated at the junction between the vertebra and the fifth left rib. After erosion of the ribs above and below and of the T4 and T5 vertebral bodies, the tumour extended across the lateral opening like a neurofibroma, until it compressed the spinal cord. A second case was reported by Twersky et al. (1975). A 12 year old child suffered from walking difficulty for three and a half weeks. Operation disclosed an osteochondroma developing from the vertebral junction of the fifth rib on the right and invading the $\mathrm{T} 4, \mathrm{~T} 5, \mathrm{~T} 6$, and $\mathrm{T} 7$ vertebral bodies. Natarajan et al. (1976) quoted a similar case with generalised exostoses.

Madigan et al. (1974) found 13 cases of generalised exostoses, to which we may add that presented by Chiurco (1970) which was at $C 1$ and $C 2$ vertebral level in a 16 year old boy and was fatal. In $50 \%$ of cases, the exostosis involved the cervical cord and, in six cases out of seven, the posterior arch of the atlas. The course was insidious; the first signs only appeared in the second or third decade of life. This is why it is necessary to seek, as a routine, the vertebral lesions in this disease, especially as these occur in $7 \%$ of cases depending on the series (Carmel and Cramer, 1968).

The treatment of osteochondromas is surgical removal as early as possible in view of the risk to life and the possibility of serious sequelae.

\section{References}

Carmel, P. W., and Cramer, F. J. (1968). Cervical cord compression due to exostosis in patient with hereditary multiple exostoses. Journal of Neurosurgery, 28, 500-503.

Chiurco, A. A. (1970). Multiple exostoses of bone with fatal spinal cord compression. Neurology 
(Minneapolis), 20, 275-278.

Dahlin, D. C. (1970). Bone Tumors. General Aspects and Data on 3987 Cases. Charles C. Thomas: Springfield, Illinois.

Madigan, R., Worral, T., and McClain, E. J. (1974). Cervical cord compression in hereditary multiple exostosis. Journal of Bone and Joint Surgery, 56-A, 401-404.

Mitsumori, K., Otsua, K., Twasaki, Y., and Yada, K. (1975). Osteochondroma of the cervical spine. A case report. Neurological Surgery (Tokyo), 3, 867871.

Murray, R. O. (1969). In Textbook of Radiology. Edited by D. Sutton and R. G. Grainger, pp. 102103. Churchill Livingstone: Edinburgh and London.
Natarajan, M., Balakrisnan, D., and Srinivasan, V. (1976). Solitary osteochondroma causing spinal cord compression. Internal Surgery, 61, 494-495.

Rose, E. F., and Fekete, A. (1964). Odontoid osteochondroma causing sudden death. American Journal of Clinical Pathology, 42, 606-609.

Thomas, M. L., and Andress, M. R. (1971). Osteochondroma of the cervical spine causing cervical compression. British Journal of Radiology, 44, 449451.

Twersky, J., Kassner, G., Tenner, M., and Camera, A. (1975). Vertebral and costal osteochondromas causing spinal cord compression. American Journal of Roentgenology and Nuclear Medicine, 124, 124128. 